\title{
Effect of hydraulic and mechanical characteristics of sediment layers on water film formation in submarine landslides
}

\author{
Shogo Kawakita ${ }^{1,2}$, Daisuke Asahina ${ }^{2^{*}} \mathbb{D}$, Takato Takemura ${ }^{3}$, Hinako Hosono ${ }^{3}$ and Keiji Kitajima
}

\begin{abstract}
Through two lab-scale experiments, we investigated the hydraulic and mechanical characteristics of sediment layers during water film formation, induced by elevated pore pressure-considered one of the triggers of submarine landslides. These involved (1) sandbox experiments to prove the effect of water films on mass movement in low slope gradients and (2) experiments to observe the effect of the tensile strength of semi-consolidated sediment layers on water film formation. Portland cement was used to mimic the degree of sediment cementation. We observed a clear relationship between the amount of cement and pore pressure during water film formation; pressure evolution and sediment deformation demonstrated the hydraulic and mechanical characteristics. Based on the results of these experiments, conditions of the sediment layers during water film formation are discussed in terms of pore pressure, permeability, tensile strength, overburden pressure, and tectonic stresses. The results indicate that the tensile strength of the sediment interface provides critical information on the lower limit of the water film formation depth, which is related to the scale of potential submarine landslides.
\end{abstract}

Keywords: Water film, Pore pressure, Submarine landslides, Layer interface, Tensile strength

\section{Introduction}

Submarine landslides are known to damage offshore and coastal infrastructure and cause damaging tsunamis (Moore et al. 1989; Hampton et al. 1996; Locat and Lee 2002). The destabilization of submarine sediments is possibly triggered by elevated pore-fluid pressure, which spreads across sediment layer interfaces and can reduce their shear strength. The occurrence and evolution of pore pressure formation in sediments is influenced by their hydraulic and mechanical (HM) conditions, such as permeability, strength, and overburden as well as tectonic stresses (Jolly and Lonergan 2002; Elger et al. 2018). A better understanding of such conditions associated with sediment layers and interfaces is important for predicting and mitigating geohazards related to submarine landslides.

\footnotetext{
* Correspondence: d-asahina@aist.go.jp

${ }^{2}$ Geological Survey of Japan, AIST, Tsukuba, Ibaraki 305-8567, Japan

Full list of author information is available at the end of the article
}

Submarine landslides induced by elevated pore pressure have been studied by field observations, seismic reflection surveys, physical experiments, and numerical simulations (Rzadkiewicz et al. 1997; Biscontin et al. 2004; Gee et al. 2007; Stigall and Dugan 2010; Otsubo et al. 2018). For example, the relationship between submarine landslides caused by elevated pore pressure and gas hydrates has been studied (Sultan et al. 2004; Berndt et al. 2012; Elger et al. 2018). Dissociation of gas hydrates reduces sediment permeability, resulting in the accumulation of free gases and the elevation of pore pressure. Elger et al. (2018) used seismic data to show that elevated fluid pressures in the gas hydrate stability zone moved to shallower layers or the sediment interface through pipe formation. They also showed that lateral overpressure built up in shallow sediments possibly triggers submarine landslides. Morita et al. (2012) used 3D seismic data to show a typical slumping deformation, accompanied by parallel dikes that are considered as the 
evidence of dewatering structures. They discussed the relationship between seafloor stability and dewatering structure, which was closely related to natural gas distribution and slumping formation mechanisms. The effect of compressibility and sedimentation rate on overpressure generation has also been investigated to understand low-gradient and large submarine landslides (Urlaub et al. 2015). Utsunomiya et al. (2019) surveyed the stratigraphy and material features of coarse-ash and lapillituff beds, with intruding clastic dykes due to elevated fluid pressure, to understand the preferential formation of slip planes in submarine landslides.

An elevated fluid pressure creates a space (or propagates a crack) within sediments in various directions, which affects seafloor stability, depending on the HM conditions and anisotropy of the surrounding sediments. For example, horizontal openings in the sediments can be classified as water films, layered fractures, or sills, whereas vertical openings are recognized as pipings, sand boils, or dykes (Cheng et al. 2001; Gudmundsson and Brenner 2002; Jolly and Lonergan 2002). The fluid pressure conditions needed to form such spaces in unconsolidated sediments were studied through theoretical and laboratory experiments ( $\mathrm{Lu}$ et al. 2014). Tsuji and Miyata (1987) used the sand-clay mixed analog sediments to study the structure developments of the elevated pore pressure induced by upward fluid flow. Their observation showed various structures of the pore pressure, such as a dish-shaped structure formed in the horizontal direction, vertical dewatering structures, and their connectivity. Sandstone dykes and sills have been investigated for geological evidence and their controlling mechanisms related to tectonic and overburden stresses (Jolly and Lonergan 2002).

Elevated fluid pressure within sediment layers induces mechanical changes (i.e., effective normal stress and shear strength reduction) and potentially triggers submarine landslides (Field et al. 1982; Hampton et al. 1996). Water films have been considered as a possible form of elevated pore pressure in the sediment layer, and their depth and lateral scale could affect the mobility of submarine landslides (Kokusho 2003). Kokusho et al. $(1999,2000)$ conducted sandbox experiments to study water film formation by liquefaction; the effect of a low permeability layer (silt seam) on the water film and its dynamic characteristics were observed. Liu and Qiao (1984) performed shake table tests on two-layer deposits and observed the development of a water lens to a water interlayer (or water film). Centrifuge shake table tests demonstrated the formation of water interlayers in layered sand (Fiegel and Kutter 1994) and scaling laws of submarine landslides with different gravity levels (Gue et al. 2010).
As mentioned above, studies on the effect of water film formation on mass movements have primarily been conducted in unconsolidated sediments. However, research on HM conditions of semi-consolidated sediment layers during water film formation is scarce. This is partly due to the difficulty in measuring properties of semi-consolidated sediment layers (e.g., tensile strength), especially at the sediment interface. Information on HM conditions and sediment properties is critical to understand the lower limit of the water film formation depth, which could affect the scale of submarine landslides.

This paper aims to better understand HM characteristics as well as to constrain the conditions of sediment layers during water film formation; of particular interest is the process of water film formation in unconsolidated and semi-consolidated sediment and its dependence on the surrounding conditions. We present two lab-scale experiments that studied the formation of water films associated with elevated pore pressure. The first sandbox experiment demonstrates the liquefaction of unconsolidated sediments to understand the effect of a water film on the mass movement. The results helped to visualize the three stages related to the water film phenomenon. The second experiment was conducted to study water film formation due to an elevated pressure by upward fluids flowing into semi-consolidated sediments, similar to those found in gas hydrate-bearing sediments. The effect of the tensile strength of a bedding plane on water film formation using artificial semi-consolidated sediments was investigated. In natural sediments, bedding planes are consolidated by burial diagenesis with cementing materials. Here, Portland cement was used as cementing material to control the degree of consolidation of the bedding plane. The results revealed the relationship between the amount of Portland cement and pore pressure to form a water film. HM conditions of the sediment layers during water film formation are discussed in terms of pore pressure, overburden stresses, sediment permeability, and tensile strength.

\section{Sandbox test: water film effect on mass movement}

\subsection{Experimental setup}

Through a series of sandbox experiments, we observed mass movement in low slope gradients induced by a water film. Figure 1 illustrates a sediment analog model with three layers of commercial silica sand, filled in an acrylic box with dimensions of $600 \times 300$ $\times 360 \mathrm{~mm}$; and a fine sand layer sandwiched between coarse ones. Figure 2 shows the accumulation curve for the grain sizes of two types of silica sand. We also performed a single-layer sandbox test using coarse particles to study the effect of fine sand layers on the mass movement. 


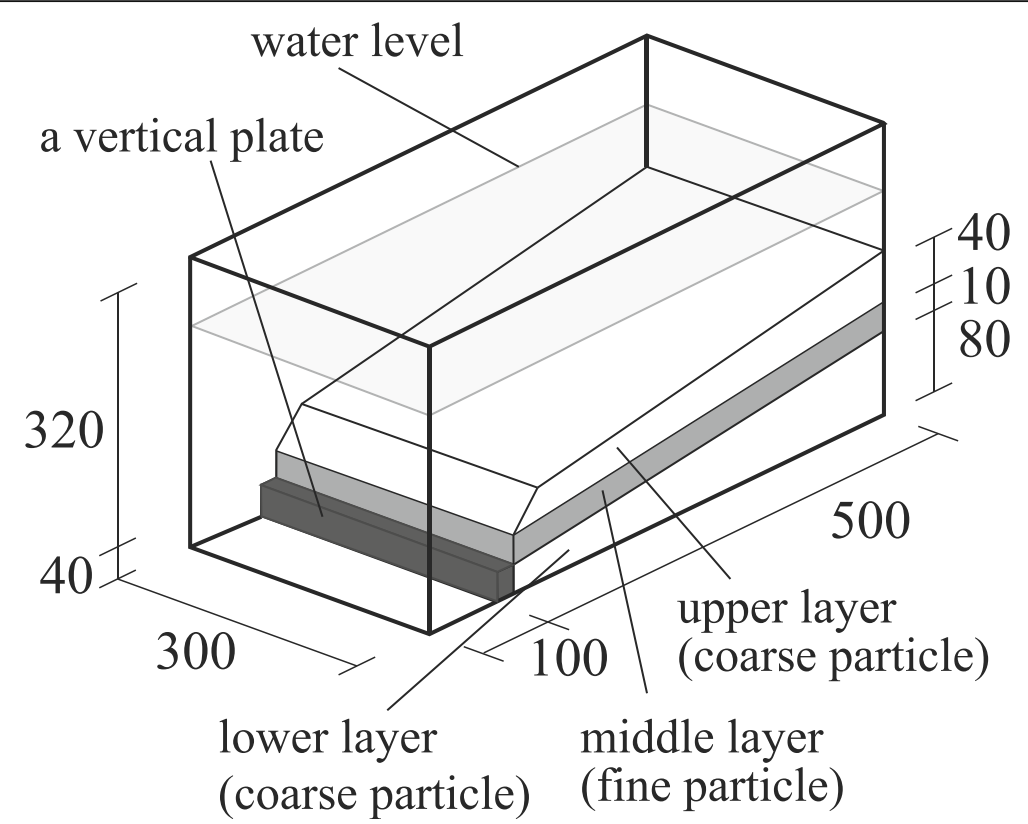

Fig. 1 Illustration showing the saturated sand layers and the position of the vertical plate

The sand was carefully sprinkled into the box with an angle of inclination, filled with water to a certain depth, ensuring no pre-compaction. The sediment model included an upper layer ( $40 \mathrm{~mm}$ thick), a middle layer (10 $\mathrm{mm}$ thick), and a bottom layer (40 and $80 \mathrm{~mm}$ thick at each end) (Fig. 1). The middle layer was treated as a lowpermeability layer, while the bottom layer worked as a liquefaction layer. The thickness and slope angle were kept constant throughout the layers within a practically controllable range. A concrete mixing vibrator $(3 \mathrm{~Hz})$ was used to generate excitation, liquifying the sand layers.
In general, when water-immersed sand is shaken in a small-scale box, it starts to move, and an initially inclined layer gets easily leveled. Therefore, it is difficult to observe both the formation of a water film due to liquefaction and gravity-driven flow as a series of processes in one experiment. Hence, we devised a mechanism to prevent lateral flow in the bottom layer by setting a vertical plate inside the box (Fig. 1). The moving distance of the upper layer was measured by tracking soil particles using video images. This study describes the results of one representative experiment. In this study, the term

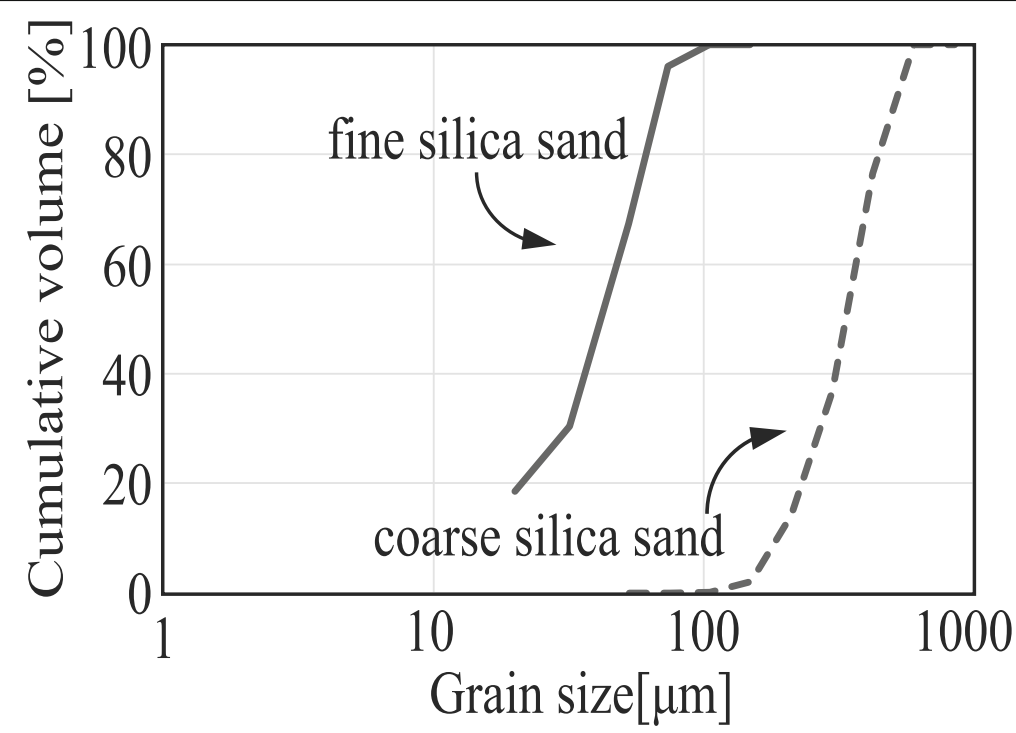

Fig. 2 Grain size accumulation curve for fine and coarse silica sand 
liquefaction indicates that the pore pressure in the sand layer increases by excitation, and the sand particles are no longer bonded. When the sand is liquefied, the total stress between the sand particles becomes equal to the pore pressure (i.e., excess pore pressure ratio $>1$ ).

\subsection{Results}

Figure 3 shows the evolution in the movement of singlelayer coarse sand. Saturated sand started compacting in a vertical direction immediately after excitation (Fig. 3b). A small amount of sand moved to the left of the vertical plate; thereafter, the sand slope stabilized to a nearly flat surface (Fig. 3c). Overall, the movement of sand particles was limited. Neither a water film nor a large mass movement was observed.

In contrast, the results of the three-layer sandbox clearly showed distinct mass movement processes associated with water films (Fig. 4). First, the waterimmersed sand compacted in a vertical direction immediately after excitation and eventually settled (Fig. 4b). Then, a water layer formed at the interface between the middle and bottom layer (Fig. 4c), known as the water film phenomenon. In the early stage of the water film formation, two large dish-structures were observed. Subsequently, the dish-structures were combined into one to form the water film; its visible length was $\sim 400 \mathrm{~mm}$ with no discontinuity and its thickness was about $0.5-2$ $\mathrm{mm}$. Thereafter, a large amount of sand above the water film moved to the left (Fig. 4d, e). As soon as this lateral movement was triggered, the water film was not visible and the fine sand in the middle layer moved slightly upward to the upper layer surface, causing multiple sand boils (or piping) (Fig. 4e). As the intensity of sand boiling gradually diminished, the sand settled by filling up the space on the left. The maximum post liquefaction settlement achieved was about $55 \mathrm{~mm}$. Particle movement in the horizontal direction of the single-layer test was $27 \mathrm{~mm}$, and that of the three-layer test was 116 $\mathrm{mm}$.

The above observations imply several HM interactions at layer interfaces. Excitation of the sandbox induced liquefaction, during which the water-immersed sand segregated into water and sand. Water, flowed into the bottom layer, rose and the water accumulated below the middle fine sand layer that acted as a permeability barrier due to a permeability contrast between the bottom and middle layer. The water film reduced the shear resistance at the layer interface. The large mass movement with low gradients can be explained by a reduced shear strength associated with the water film, recognized as a specific feature of submarine landslides (Kokusho 1999; Kokusho 2003). Moreover, intense sand boiling during the lateral mass movement indicated elevated pressure in the water film. Pipe structures formed in the upper layer, which became elongated and thinned due to lateral mass movement. Kvalstad et al. (2005) presented a similar mechanism, showing evidence from field surveys of submarine landslides. The upper layer was elongated, and normal faults formed around the submarine landslide. The pipe structures indicated an elevated pore pressure in sediments and were recognized as common phenomena accompanying submarine landslides (Morita et al. 2012; Elger et al. 2018; Utsunomiya et al. 2019).

Two conditions are necessary to enable lateral mass movement: the presence of a permeability barrier, essential to water film formation (discussed in detail in Section 4), and the upper layer needs to have space for movement before the inclination of sand stabilizes. As mentioned, the vertical plate facilitates the separation of two processes: sand liquefaction in the bottom layer and
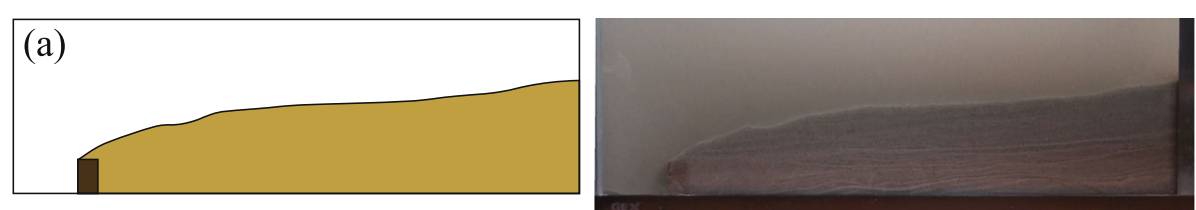

(b)
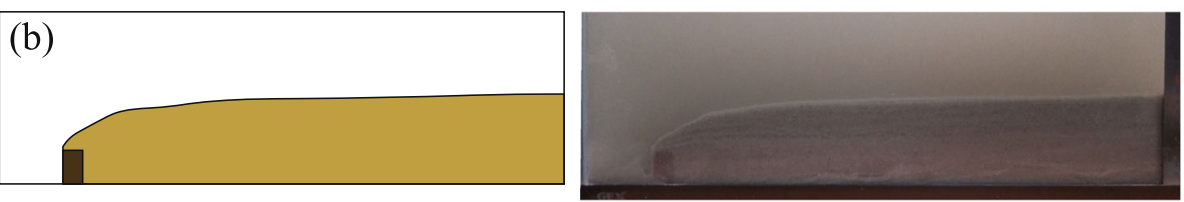

(c)
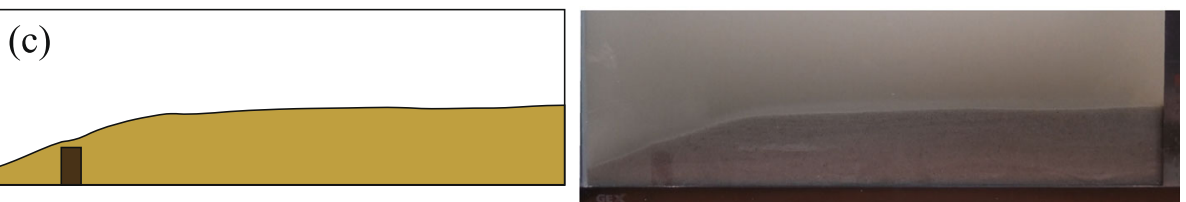

Fig. 3 Single-layer sandbox test; frontal view in illustration (left) and actual image (right) at different stages: a Before excitation, b during liquefaction, and $\mathbf{c}$ after mass movement. In the illustration, brown and dark yellow represent the vertical plate and coarse sand, respectively 

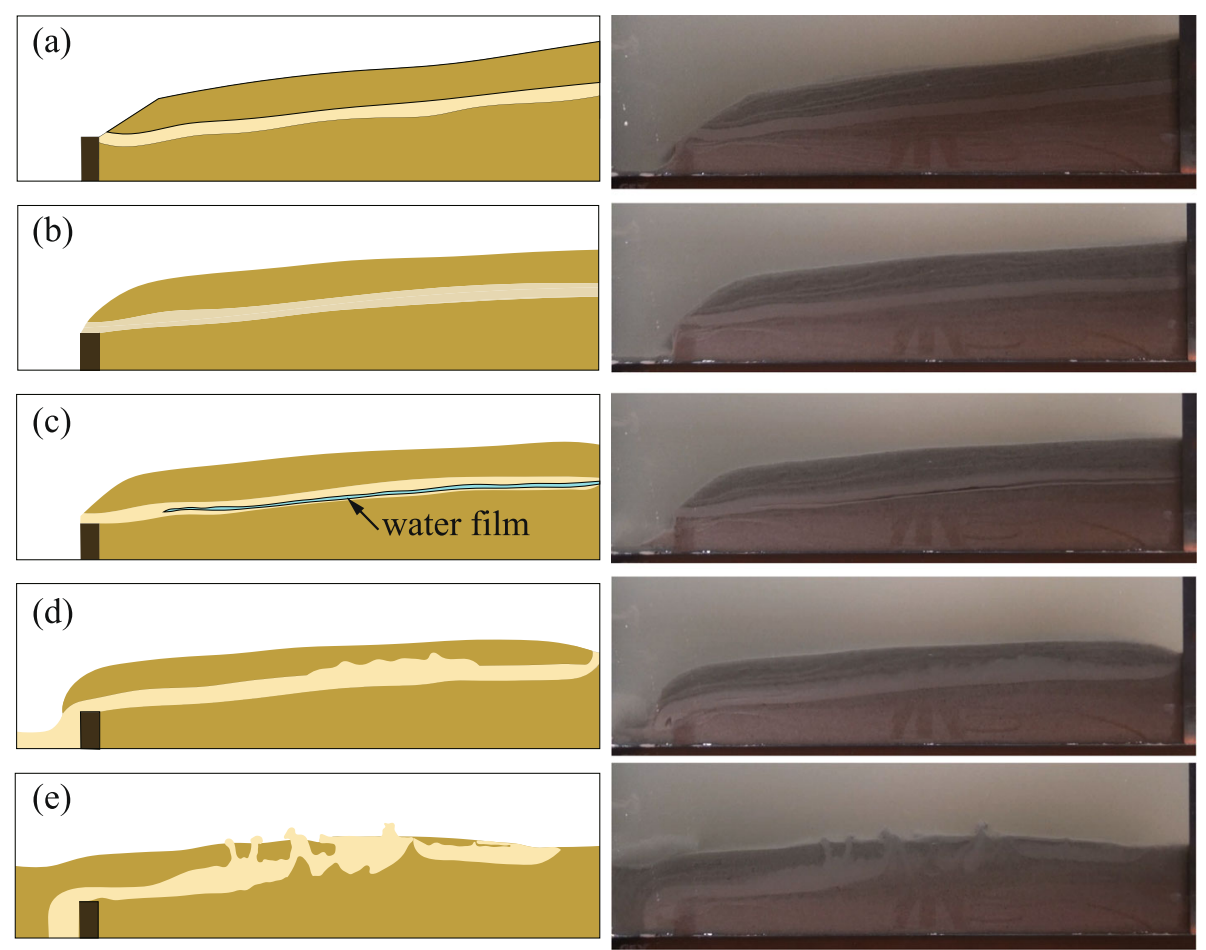

Fig. 4 Three-layer sandbox test; frontal view in illustration (left) and actual image (right) at different stages: a Before excitation, b during liquefaction, c during water film formation, $\mathbf{d}$ beginning of lateral movement, and $\mathbf{e}$ after large mass movement with sand boiling. In the illustration, brown represents the vertical plate, while dark and light yellow represent coarse and fine sand, respectively. Blue represents a water film

gravity-driven flow caused by the water film. Although the sandbox test demonstrates the effect of a water film on lateral mass movements, it has limitations in simulating actual submarine landslides, such as the box size, excitation period, influence of the vertical plate that prevents the lateral flow of the bottom layer, and scaling effect of the mass movement, etc. The following section introduces one of these aspects: the effect of the tensile strength of semi-consolidated sediment layers on water film formation.

\section{Tensile strength test of sediment layer interface \\ 3.1 Specimen description}

The relationship between the tensile strength of semi-consolidated sediment and water film formation was studied through an analogous model composed of a two-layer sediment, bentonite and Toyoura sand. Bentonite was used due to sufficient contrast of material properties for water film formation, unobtainable if only sand was used. The bentonite used in this study contained smectite (46-49\%), chalcedony $(37-38 \%)$, and other materials $(13-17 \%)$, and was considered as impermeable (Shirazi et al. 2010). Figure 5 shows the grains size accumulation curve for Toyoura sand and Bentonite. Ordinary Portland cement was used as a binding material to change the cementation of the sediments and their interface. Two-layer specimens were cast in an acrylic hollow cylindrical cell (length: $70 \mathrm{~mm}$, inner diameter: 37.5 $\mathrm{mm}$ ), as shown in Fig. 6. Table 1 shows the mixture proportions of the sediment models. The thickness of the bentonite and Toyoura sand layer was set to $45 \mathrm{~mm}$ and $40 \mathrm{~mm}$, respectively, and kept constant to retain the same contact area between the specimen and inner wall of the acrylic cell. For both layers, the weight ratio of cement to cement composites ("CC ratio") was set to $0 \%, 10 \%, 20 \%, 30 \%$, and $40 \%$, respectively. For the Toyoura sand layer, the amount of water to the cement composites was kept at $20 \%$. Because the workability of the bentonite layer is greatly affected by the amount of water, we had to add a certain amount of water to obtain adequate workability. For the bentonite layer, the amount of water that can be added was limited to $60 \mathrm{~g}$. This amount was determined in such a way that adequate workability is achieved for the $0 \% \mathrm{CC}$ ratio, which had the least workability. We carefully cast the bentonite layer to avoid generating a flow path between the bentonite layer and the inner wall of the acrylic cell. The top and bottom of the acrylic cell were sealed with a vinyl sheet to prevent drying during curing. The two-layer specimen was cured 


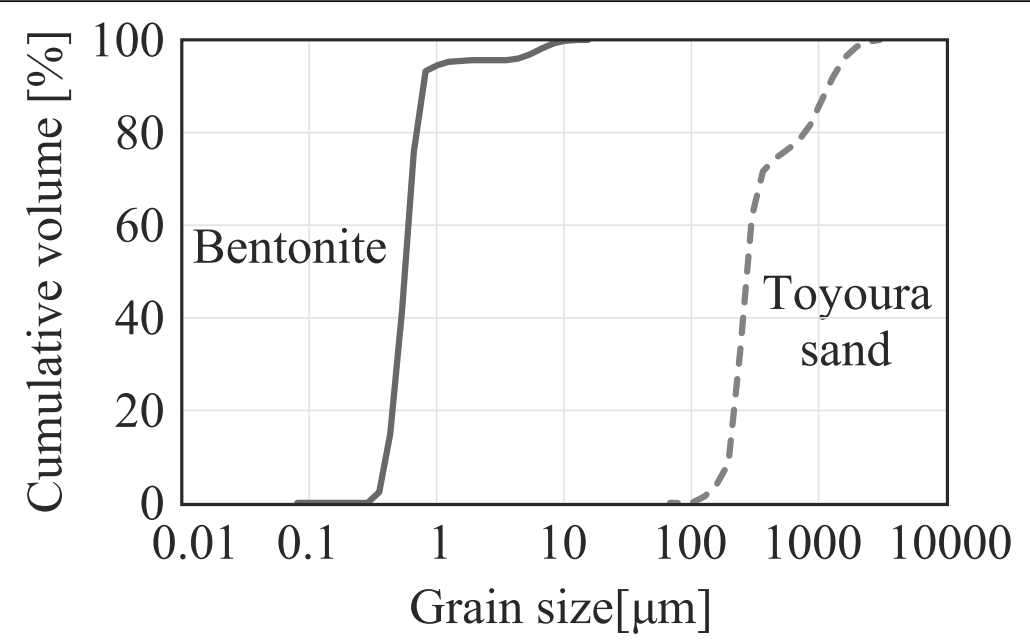

Fig. 5 Grain size accumulation curve for Toyoura sand and Bentonite

with pre-compression under a steel weight (to give a dead load of $13.7 \mathrm{~N}$ ) for 3 days.

The bentonite layer is used to provide sufficient contrast between the upper and bottom layers in the analog model, but there are differences in the conditions with the actual seafloor. The actual seafloor sediments are usually saturated, while the bentonite layer is not as easy to control for saturation due to its impermeable and high swelling properties. Also, submarine sediments may be more permeable rather than impermeable like bentonite. The influence of these aspects of bentonite is beyond the topic of this paper but will study in a subsequent paper.

\subsection{Equipment and experimental procedure}

The water film formation was studied by upward fluids flowing into semi-consolidated sediments. Figure 6 illustrates the experimental setup. It was comprised of hydraulic loading systems, measuring units, a reaction frame, and a hollow acrylic cylinder to visualize the process during water film formation. Hydraulic loading was manually controlled by an air pump. Pressure sensors with accuracies of $0.3 \mathrm{kPa}$ (up to a maximum of 1 $\mathrm{MPa}$ ) were attached. Three pressure sensors were placed accordingly to measure fluid pressure. A dial gauge was attached to the top pedestal to measure vertical specimen deformation (Fig. 6a). Filter paper and porous fabric were placed at the base of the specimens and outlets of

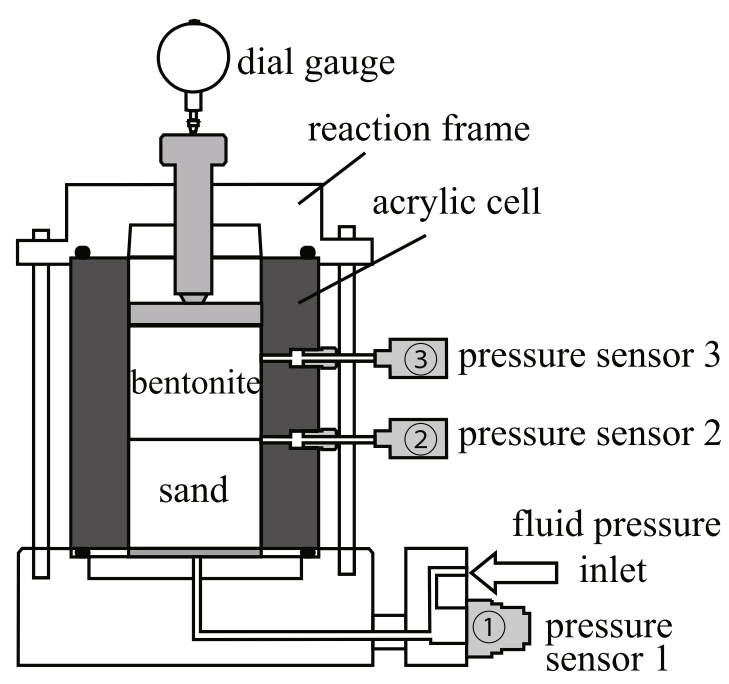

(a)

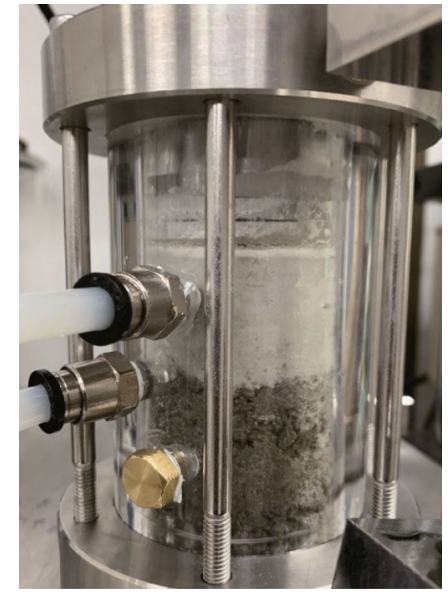

(b)

Fig. 6 Experimental configuration: a Schematic representation of the tensile test for the two-layer specimen. Fluid pressures were measured by pressure sensors installed at the fluid pressure inlet (bottom), layer interface, and upper layer; and $\mathbf{b}$ photograph of a specimen showing flow lines to the pressure sensors, a specimen-filled acrylic cell, and reaction frame 
Table 1 Mixture proportions of Toyoura sand and bentonite layers

\begin{tabular}{|c|c|c|c|c|c|c|}
\hline \multirow{2}{*}{$\begin{array}{l}\text { CC } \\
\text { ratio } \\
\text { (\%) }\end{array}$} & \multicolumn{3}{|c|}{ Toyoura sand layer } & \multicolumn{3}{|c|}{ Bentonite layer } \\
\hline & Sand $(g)$ & Cement (g) & Water $(\mathbf{g})$ & Bentonite (g) & Cement (g) & Water (g) \\
\hline 0 & 60.0 & 0.0 & 0.0 & 20.0 & 0.0 & 60.0 \\
\hline 10 & 60.0 & 6.7 & 13.3 & 18.0 & 2.0 & 60.0 \\
\hline 20 & 60.0 & 15.0 & 15.0 & 16.0 & 4.0 & 60.0 \\
\hline 30 & 60.0 & 25.8 & 17.2 & 14.0 & 6.0 & 60.0 \\
\hline 40 & 60.0 & 40.0 & 20.0 & 12.0 & 8.0 & 60.0 \\
\hline
\end{tabular}

For Toyoura sand, the amount of water to the cement composites was set to $20 \%$ for all specimens. For the bentonite layer, $60 \mathrm{~g}$ of water was used for all specimens. This amount of water provides adequate workability for the $0 \%$ CC ratio, which had the lowest workability

the pressure sensor, respectively, to prevent the fluid path from being clogged.

The experimental flow is as follows.

Step 1. Toyoura sand and bentonite were mixed with cement and water, and then placed in the acrylic cell for 3 days curing.

Step 2. The acrylic cell was set in the reaction frame, and the measuring devices were attached as shown in Fig. 6a. The vertical overload was the weight of the top pedestal and the bentonite layer, whereas confinement pressure was not applied.

Step 3. The water pressure was incrementally applied to the bottom of the specimen from a pedestal fixed to the acrylic cell.

Step 4. At some point, the bentonite layer rose, and a space filled with water was formed at the layer interface (i.e., water film). The existence of a water film was recognized by deformation, fluid pressure, and visual inspection.

When a water film forms at the layer interface, the mechanical balance can be expressed as:

$$
P_{\mathrm{wf}}=T+W / A+C
$$

where $P_{\mathrm{wf}}$ is the fluid pressure of the water film, $T$ is the tensile strength of the layer interface, $W$ is the overburden load (i.e., self-weight above the water film), $A$ is the specimen's cross-sectional area, and $C$ is the cohesion between the upper layer of the specimen and the inner wall of the cell. To measure the cohesion, $C$, we conducted a simple push-out test. For the push-out test, only one bentonite layer was prepared in the acrylic cell, in the same manner as in the tensile test. We measured the push-out force using a steel piston attached to the reaction frame and load cell.

\subsection{Results}

Figure 7 shows photographs of the specimen before and after water film formation. Figure 8 shows the evolution of pore-fluid pressure and vertical displacement at different stages for five specimens with different $\mathrm{CC}$ ratios.
The results presented here are a subset of experiments performed on 14 specimens.

Initially, we visually observed that water penetrated the Toyoura sand layer when fluid pressure was applied from below the specimen. Figure $8 \mathrm{a}-\mathrm{d}$ shows an increase in inlet pressure, followed by an increase in layer interface pressure. A water film formed at the layer interface only for specimens with $0 \%, 10 \%, 20 \%$, and $30 \% \mathrm{CC}$ ratios (gray areas in Fig. 8a-d). After the formation of a water film, displacement increased, while the bentonite layer started to rise (Fig. 7b). Simultaneously, the layer interface pressure first decreased and then increased, which was caused by the creation of space due to the separation of the sediment layers, and the volume of the water film increased. The process of water film formation showed a similar tendency, regardless of the $\mathrm{CC}$ ratio. The fluid pressure in the upper layer was unchanged during the test.

With an increasing $\mathrm{CC}$ ratio, the tensile strength at the layer interface increased, while the permeability of the sand layer decreased, making it difficult for the fluid pressure to increase at the layer interface, which led to a delay in water film formation. For the $40 \% \mathrm{CC}$ ratio (Fig. $8 \mathrm{e})$, the layer interface pressure remained unchanged, and a water film did not form, the formation of which was hindered before reaching the maximum capacity of the test equipment (1 MP).

Figure 9 shows the maximum fluid pressure of the layer interface prior to water film formation as well as the tensile strength of the layer interface calculated by Eq. 1 as functions of the $\mathrm{CC}$ ratio. As mentioned above, the cohesion between the bentonite layer and the inner wall of the acrylic cell was measured through the push-out test. The cohesion was calculated by dividing the push-out force by the contact area between the bentonite layer and the inner wall. The cohesion was measured to be $0.76,3.28$, and 3.53 $\mathrm{kPa}$ for a CC ratio of $10 \%, 20 \%$, and $30 \%$, respectively. These cohesion values were less than $5 \%$ of the maximum pore pressure during water film formation. Because of the low cohesion between the bentonite 


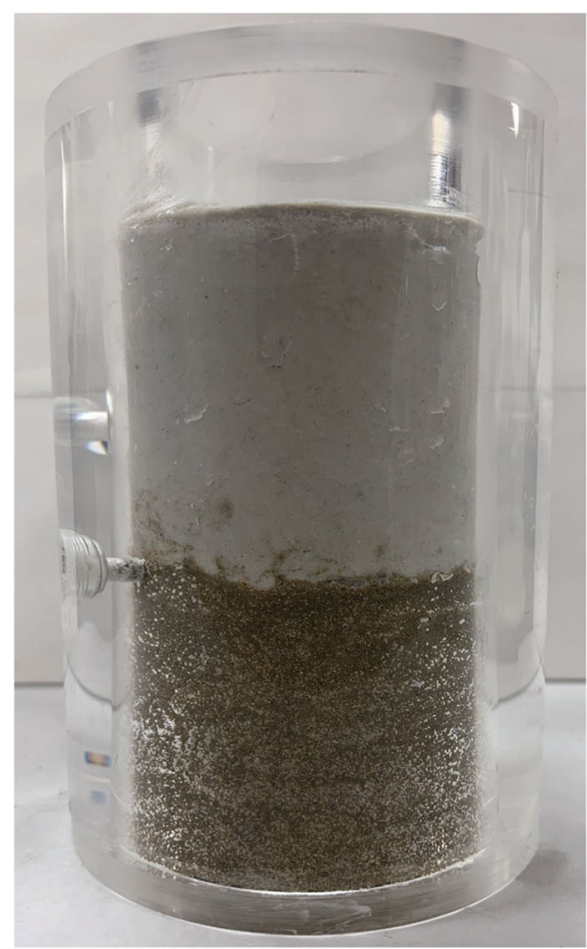

(a)

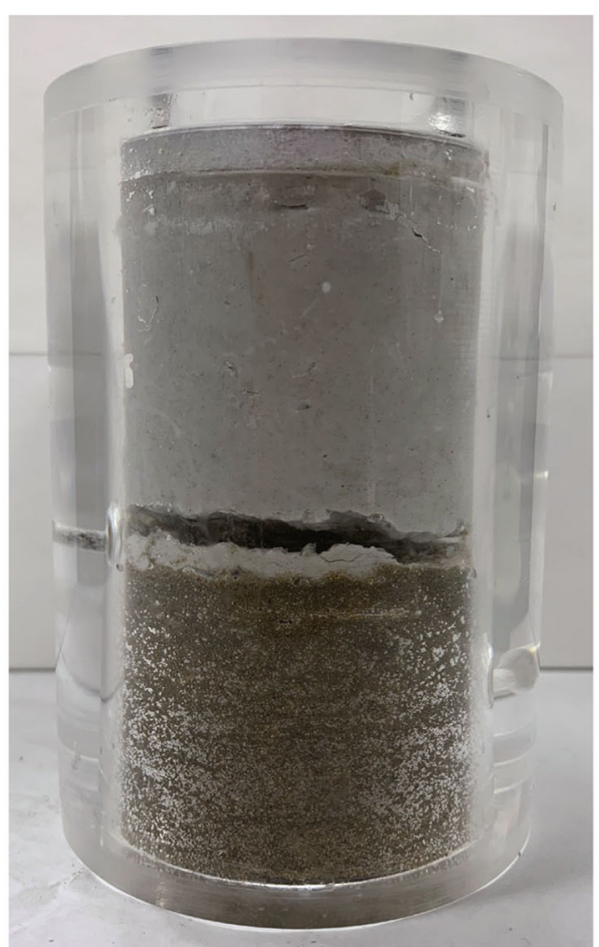

(b)

Fig. 7 Photograph of the two-layer specimen: $\mathbf{a}$ before and $\mathbf{b}$ after the experiment
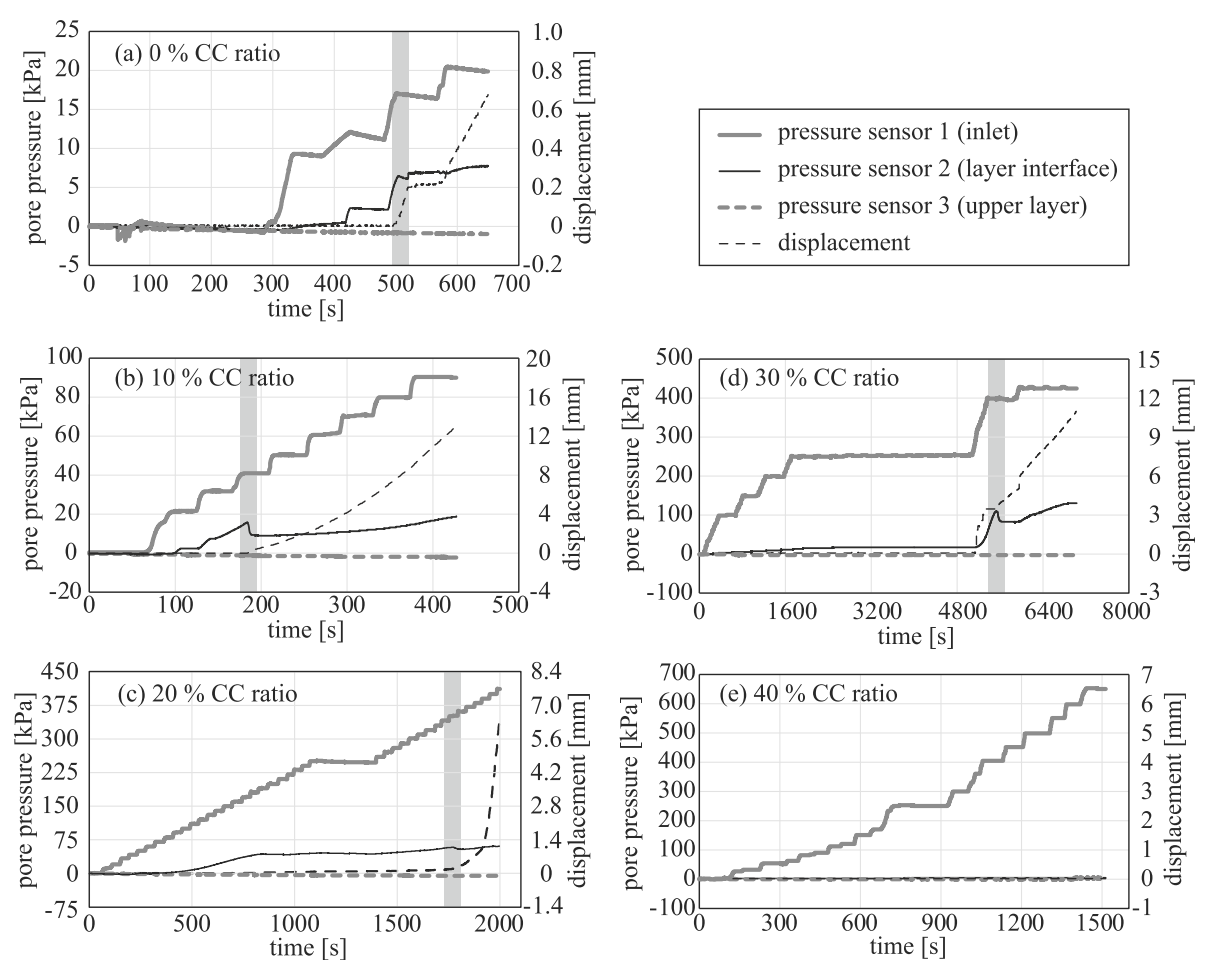

Fig. 8 Responses recorded at different CC ratios: a 0\%, b 10\%, c 20\%, d 30\%, and e 40\%. The scale varies between specimens. Gray areas indicate periods of water film formation with a notable decrease in pressure sensor 2 and an increase in deformation 


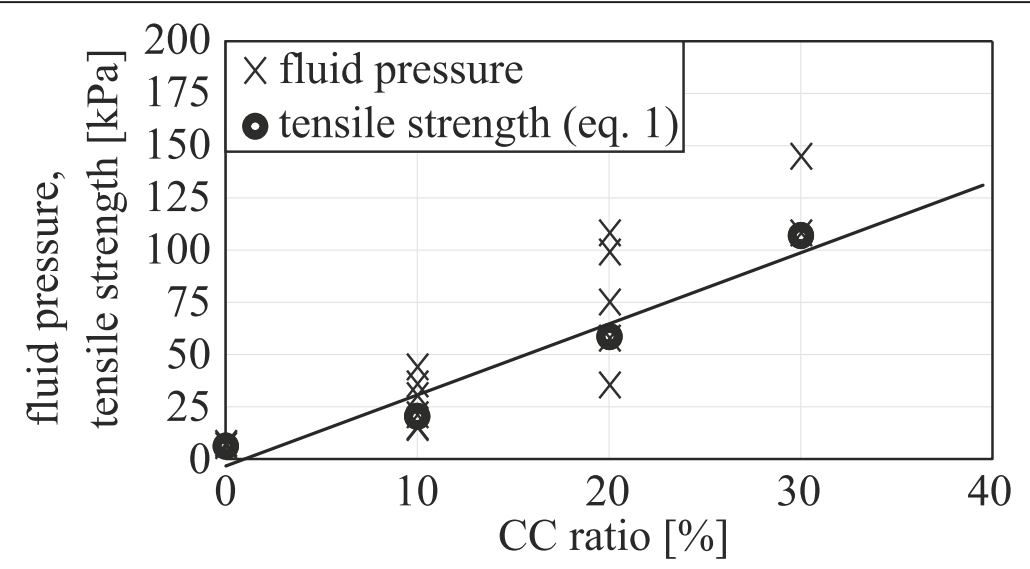

Fig. 9 Fluid pressure and tensile strength versus $C C$ ratio

layer and the inner wall, the vertical deformation of the bentonite layer, prescribed by the pore pressure, was also small. Therefore, the lateral expansion (i.e., Poisson effect) of the bentonite was considered small, which would result in a negligible frictional resistance. During water film formation, a space filled with water was created at the layer interface, which was visually confirmed. Therefore, the pore pressure was assumed to apply uniformly to the upper layer. Based on these assumptions, the cohesion values were used to calculate the tensile strength according to Eq. (1). Tensile strength was calculated using the average fluid pressure (Fig. 9). The pressure magnitudes and tensile strength increased almost linearly with an increasing $\mathrm{CC}$ ratio, although there was some variation.

\section{Discussion}

Based on the experiments discussed earlier, we summarize two basic conditions essential for water film formation in sediment layers. To simplify the complex HM conditions of the seafloor, we consider simple two-layered sediment, with the following assumptions:

- Assuming two simple horizontal layers; therefore, a water film forms horizontally.

- Assuming three material phases: upper and lower sediment, and the interface between them.

- Neglecting the viscous effect at the tip of sediment separation (i.e., crack tip) (Jolly and Lonergan 2002).

- Assuming that water flows from the lower layers due to liquefaction or gas hydrate-bearing sediments.

First, we consider a hydraulic condition to generate hydrostatic pore pressure, $P_{\mathrm{p}}$, and exceed pore pressure, $P_{\mathrm{ex}}$, at the layer interface. As a condition for generating a pressure difference at the layer interface, the relationship between the permeability of the upper layer, $k_{\text {up }}$, and lower layer, $k_{\text {low }}$, is as follows:

$$
k_{\text {up }}<k_{\text {low }}
$$

As demonstrated earlier, this condition provides a seal, causing elevated pressure below the upper layer (Osborne and Swarbrick 1997; Jolly and Lonergan 2002). The pore pressure at the layer interface can be increased by supplying fluid at a sufficient rate to the layer interface, and if the upper layer has a sufficiently low permeability. If pipe structures or clastic intrusions form pathways for over-pressured fluids from the lower layer to the layer interface, the permeability of the lower layer may not be influential.

Next, we consider mechanical conditions for an elevated pore pressure to form a space (or propagate a crack) within the sediment. Water films can be classified as geometrical forms by which elevated pore pressures can mechanically generate spaces in the sediment. For simplicity, we focus on two directions, horizontal and vertical, as the space extended by elevated pore pressures. To form a space horizontally (i.e., water film), the mechanical balance becomes

$$
P_{\mathrm{P}}+P_{\mathrm{ex}}>\sigma_{\mathrm{v}}+T_{\mathrm{v}}
$$

where $T_{\mathrm{v}}$ is the tensile strength at the layer interface and $\sigma_{\mathrm{v}}$ is the overburden stress (Fig. 10a). To form a space vertically, the following equation must be satisfied (Fig. $10 \mathrm{~b})$,

$$
P_{\mathrm{P}}+P_{\mathrm{ex}}>\sigma_{\mathrm{h}}+T_{\mathrm{h}}
$$

where $\sigma_{\mathrm{h}}$ is the horizontal stress and $T_{\mathrm{h}}$ is the horizontal tensile strength of the sediment (Jolly and Lonergan 2002). When space is generated vertically in the upper layer, the exceed pore pressure at the layer interface decreases, as demonstrated earlier (Fig. 4). Therefore, the 


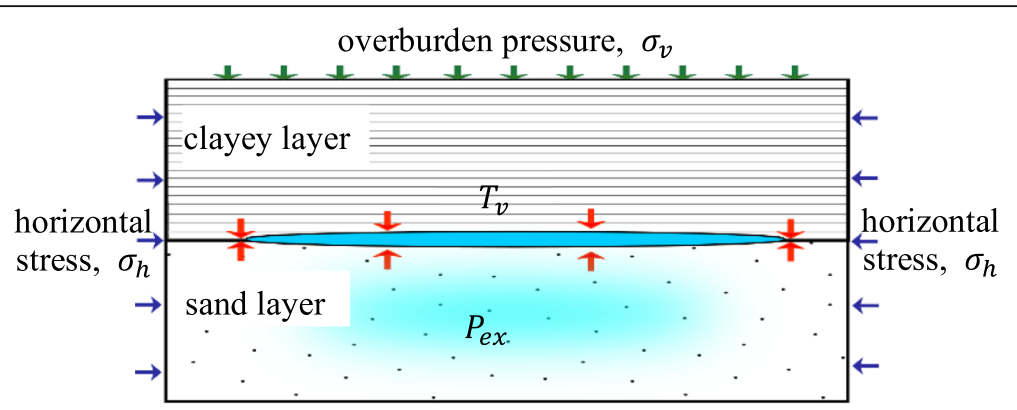

(a)

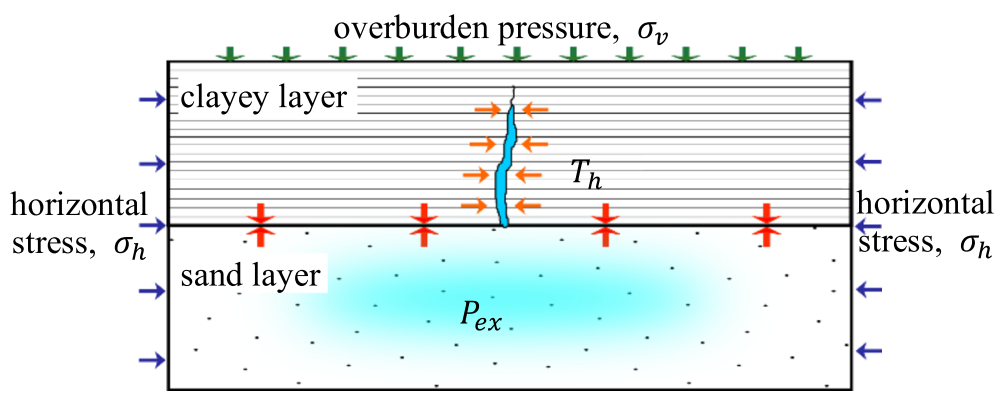

(b)

Fig. 10 Schematic cross-section of a sedimentary layer: a Horizontal crack (e.g., water film formation) and $\mathbf{b}$ vertical crack

conditions for water film formation can be expressed by combining Eqs. (3) and (4), in an opposite relationship, as follows:

$$
\sigma_{\mathrm{v}}+T_{\mathrm{v}}<P_{\mathrm{P}}+P_{\mathrm{ex}}<\sigma_{\mathrm{h}}+T_{\mathrm{h}}
$$

Although the tests in Section 3 have analogous conditions, we confirmed that there is a degree of consolidation where a water film cannot form. The maximum tensile strength measured during water film formation was about $100 \mathrm{kPa}$ at a CC ratio of $30 \%$, which was considered as the lower limit because $\sigma_{\mathrm{v}}$ was low enough to be ignored. Here, we can consider the critical tensile strength of the layer interface based on the Griffith theory (e.g., Sibson 1998), in which the criterion required for the formation of an extensional fracture is as follows:

$$
\left(\sigma_{1}^{\prime}-\sigma_{3}^{\prime}\right)<4 T_{\mathrm{v}}
$$

where $\sigma_{1}^{\prime}$ and $\sigma_{3}^{\prime}$ are the maximum and minimum effective stresses, respectively. The coefficient of earth pressure at rest, $K_{0}=\sigma_{\mathrm{h}} / \sigma_{\mathrm{v}}$ (the ratio of horizontal to vertical stress) is generally 0.25 to 0.67 in sediments (Wesley 2009). Therefore, the overburden stress is larger than the horizontal tectonic stress, especially at deeper depths. Furthermore, as consolidation and diagenesis (cementation) progress: (i) the permeability contrast between upper- and lower-layers decreases, resulting in a low pore pressure gradient; and (ii) the tensile strength of the layer interface increases, resulting in an undefinable weak interface. The greater the consolidation stress, such as in sediments with a higher overload, and the longer the consolidation time, the greater the sediment consolidation. Consequently, water films do not tend to form in general regional stress, in wellsedimented environments, and at deeper depths. However, this is not the case in areas where the horizontal stress is the maximum principal stress, e.g., the end of a slope, or the active tectonic stress associated with subduction zones (Kawamura et al. 2014). Subduction zones (even at shallower depths) are one of the possible areas where the horizontal stress becomes the maximum principal stress. Thus, submarine landslides due to water film formation could occur in semi-consolidated sediments with cohesive strength. Conditions suitable to water film formation could occur at depths shallower than where consolidation diagenesis progresses, up to a tensile strength of $100 \mathrm{kPa}$ in the subduction zone. To date, information on the tensile strength of marine sediment cores is limited. Our approach could be used to measure the tensile strength of semi-consolidated sediments to systematically estimate the critical depth of water film formation, which affects the scale of submarine landslides.

\section{Conclusions}

Physical properties of multiple sediment layers as well as the evolution of their pore pressure with subsurface instability greatly affect the scale and intensity of 
submarine landslides. Obtaining physical measurements of submarine landslides at the seafloor is challenging, largely due to difficulties in investigating relevant scales and locations. Through laboratory experiments on unconsolidated and semi-consolidated sediments, we observed hydraulic and mechanical characteristics during water film formation induced by elevated pore pressures. We first presented sandbox tests to demonstrate the effects of water film formation on the lateral mass movement. Then, the pore pressure of semi-consolidated sediments was measured during water film formation, and the effect of tensile strength was observed. Thereafter, the controlling mechanisms for water film formation were considered in terms of permeability, tensile strength, overburden pressure, and horizontal tectonic stresses.

We demonstrated the formation of water films at the interface of semi-consolidated sediments under limited conditions; submarine landslides induced by water films could occur at a sediment layer interface with progressive consolidation diagenesis, which is strongly related to the depth below the seafloor.

Although we demonstrated the effect of hydraulic and mechanical characteristics of sediment layers on water film formation, limitations exist in simulating the conditions of actual submarine landslides. Water film formation is greatly affected by both, material properties of the sediments and external loading. Therefore, further research is required to mimic conditions occurring during water film formation. A subsequent experimental study will be conducted to measure sediment tensile strength from marine cores, which will further the understanding of conditions required to form a water film.

\section{Acknowledgements}

Not applicable.

\section{Authors' contributions}

SK carried out the experimental studies and drafted the manuscript. DA proposed the topic, conceived, and designed the study. Tा designed the experiments and drafted the manuscript. HH drafted the figures and carried out the experimental studies. KK contributed to the discussion of the results. All authors read and approved the final manuscript.

\section{Funding}

This work was partially supported by JSPS KAKENHI Grant Number 19K15092 and $19 \mathrm{~K} 04603$.

\section{Availability of data and materials}

The dataset supporting the conclusions of this article is included in the article.

\section{Competing interests}

The authors declare that they have no competing interests.

\section{Author details}

${ }^{1}$ Department of Oceanic Architecture and Engineering, College of Science and Technology, Nihon University, Tokyo 101-8308, Japan. ${ }^{2}$ Geological Survey of Japan, AIST, Tsukuba, Ibaraki 305-8567, Japan. ${ }^{3}$ Geomechanics Laboratory, Department of Earth and Environmental Sciences, College of Humanities and Sciences, Nihon University, Tokyo 156-8550, Japan.
Received: 11 May 2020 Accepted: 15 September 2020

Published online: 07 October 2020

\section{References}

Berndt C, Costa S, Canals M, Camerlenghi A, Mol BD, Saunders M (2012) Repeated slope failure linked to fluid migration: the Ana submarine landslide complex, Eivissa Channel, Western Mediterranean Sea. Earth and Planetary Science Letters 319-320:65-74. https://doi.org/10.1016/j.epsl.2011.11.045

Biscontin G, Pestana JM, Nadim F (2004) Seismic triggering of submarine slides in soft cohesive soil deposits. Marine Geology 203(3-4):341-354. https://doi.org/ 10.1016/S0025-3227(03)00314-1

Cheng CM, Qingming T, Fujiao P (2001) On the mechanism of the formation of horizontal cracks in a vertical column of saturated sand. Acta Mechanica Sinica 17(1):1-9. https://doi.org/10.1007/BF02487765

Elger J, Berndt C, Rüpke L, Krastel S, Felix G, Geissler WH (2018) Submarine slope failures due to pipe structure formation. Nat Commun 9(1):715. https://doi. org/10.1038/s41467-018-03176-1

Fiegel GL, Kutter BL (1994) Liquefaction mechanism for layered soils. Journal of Geotechnical Engineering 120(4):737-755. https://doi.org/10.1061/ (ASCE)0733-9410(1994)120:4(737)

Field ME, Gardner JV, Jennings AE, Edwards BD (1982) Earthquake-induced sediment failures on a $0.25^{\circ}$ slope, Klamath River delta, California. Geology 10(10):542-546. https://doi.org/10.1130/0091-7613(1982)10\%3C542:ESFOAS\% 3E2.0.CO;2

Gee MJR, Uy HS, Warren J, Morley CK, Lambiase JJ (2007) The Brunei slide: a giant submarine landslide on the North West Borneo Margin revealed by 3D seismic data. Marine Geology 246(1):9-23. https://doi.org/10.1016/j.margeo. 2007.07.009

Gudmundsson A, Brenner SL (2002) How hydrofractures become arrested. Terra Nova 13(6):456-462. https://doi.org/10.1046/j.1365-3121.2001.00380.x

Gue CS, Soga K, Bolton MD, Thusyanthan I (2010) Centrifuge modelling of submarine landslide flows. Paper presented at the 7th International Conference on Physical Modelling in Geotechnics, Zurich, Switzerland, 28 June -1 July 2010.

Hampton MA, Lee HJ, Locat J (1996) Submarine landslides. Reviews of Geophysics 34(1):33-59. https://doi.org/10.1029/95RG03287

Jolly RJH, Lonergan L (2002) Mechanisms and controls on the formation of sand intrusions. Journal of the Geological Society 159(5):605-617. https://doi.org/ 10.1144/0016-764902-025

Kawamura K, Laberg JS, Kanamatsu T (2014) Potential tsunamigenic submarine landslides in active margins. Marine Geology 356:44-49. https://doi.org/10. 1016/j.margeo.2014.03.007

Kokusho T (1999) Water film in liquefied sand and its effect on lateral spread. Journal of Geotechnical and Geoenvironmental Engineering 125(10):817-825. https://doi.org/10.1061/(ASCE)1090-0241(1999)125:10(817)

Kokusho T (2000) Mechanism for water film generation and lateral flow in liquefied sand layer. Soils and Foundations 40(5):99-111. https://doi.org/10. 3208/sandf.40.5_99

Kokusho T (2003) Current state of research on flow failure considering void redistribution in liquefied deposits. Soil Dynamics and Earthquake Engineering 23(7):585-603. https://doi.org/10.1016/S0267-7261(03)00067-8

Kvalstad TJ, Andersen L, Forsberg CF, Berg K, Bryn P, Wangen M (2005) The Storegga slide: evaluation of triggering sources and slide mechanics. Marine and Petroleum Geology 22(1-2):245-256. https://doi.org/10.1016/j.marpetgeo. 2004.10.019

Liu H, Qiao T (1984) Liquefaction potential of saturated sand deposits underlying foundation of structure. Proceedings of the 8 World Conference on Earthquake Engineering, Vol. III, San Francisco, California,199-206.

Locat J, Lee HJ (2002) Submarine landslides: advances and challenges. Canadian Geotechnical Journal 39(1):193-212. https://doi.org/10.1139/t01-089

Lu XB, Zhang XH, Lu L (2014) Formation of layered fracture and outburst in stratums. Environmental Earth Sciences 73(9):5593-5600. https://doi.org/10. 1007/s12665-014-3813-5

Moore JG, Clague DA, Holcomb RT, Lipman PW, Normark WR, Torresan ME (1989) Prodigious submarine landslides on the Hawaiian Ridge. Journal of Geophysical Research 94(B12):17465-17484. https://doi.org/10.1029/ JB094iB12p17465

Morita S, Nakajima T, Hanamura Y (2012) Possible ground instability factor implied by slumping and dewatering structures in high-methane-flux continental slope. In: Kawamura K, Ikehara K, Ogawa Y, Urgeles R, Mosher D, Chaytor J, Strasser M (eds) Yamada Y. Submarine Mass Movement and their 
Consequences, Berlin, pp 311-320. https://doi.org/10.1007/978-94-007-21623 28

Osborne MJ, Swarbrick RE (1997) Mechanisms for generating overpressure in sedimentary basins; a reevaluation. AAPG Bulletin 81(6):1023-1041. https:// doi.org/10.1306/8626D379-173B-11D7-8645000102C1865D

Otsubo M, Naruse H, Miyakawa A (2018) Temporal changes in the internal stresses and pore pressures in a large-scale submarine mass transport deposit. Progress in Earth and Planetary Science 5(1). https://doi.org/10.1186/ s40645-018-0219-0

Rzadkiewicz SA, Mariotti C, Heinrich P (1997) Numerical simulation of submarine landslides and their hydraulic effects. Journal of Waterway, Port, Coastal, and Ocean Engineering 123(4):149-157. https://doi.org/10.1061/(ASCE)0733950X(1997)123:4(149)

Shirazi SM, Kazama H, Salman FA, Othman F, Akib S (2010) Permeability and swelling characteristics of bentonite. Journal of the Physical Sciences 5(11): 1647-1659

Sibson RH (1998) Brittle failure mode plots for compressional and extensional tectonic regimes. Journal of Structural Geology 20(5):655-660. https://doi. org/10.1016/S0191-8141(98)00116-3

Stigall J, Dugan B (2010) Overpressure and earthquake initiated slope failure in the Ursa region, northern Gulf of Mexico. Journal of Geophysical Research 115(B4). https://doi.org/10.1029/2009JB006848

Sultan N, Cochonat P, Foucher JP, Mienert J (2004) Effect of gas hydrates melting on seafloor slope instability. Marine Geology 213(1-4):379-401. https://doi. org/10.1016/j.margeo.2004.10.015

Tsuji T, Miyata Y (1987) Fluidization and liquefaction of sand beds-experimental study and examples form Nichinan Group-. Journal of the Geological Society of Japan 93(11): 791-808 (in Japanese with English abstract), doi: https://doi. org/10.5575/geosoc.93.791.

Urlaub M, Talling P, Zervos A, Masson D (2015) What causes large submarine landslides on low gradient $\left(<2^{\circ}\right)$ continental slopes with slow $(\sim 0.15 \mathrm{~m} / \mathrm{kyr})$ sediment accumulation? Journal of Geophysical Research: Solid Earth 120(10): 6722-6739. https://doi.org/10.1002/2015JB012347

Utsunomiya M, Noda A, Otsubo M (2019) Preferential formation of a slide plane in translational submarine landslide deposits in a Pleistocene forearc basin fill exposed in east-central Japan. Geological Society, London, Special Publications 477(1):241-253. https://doi.org/10.1144/SP477.3

Wesley LD (2009) Fundamentals of soil mechanics for sedimentary and residual soils 1st edition. Wiley, New Jersey, p 464

\section{Publisher's Note}

Springer Nature remains neutral with regard to jurisdictional claims in published maps and institutional affiliations.

\section{Submit your manuscript to a SpringerOpen ${ }^{\circ}$ journal and benefit from:}

- Convenient online submission

- Rigorous peer review

- Open access: articles freely available online

- High visibility within the field

- Retaining the copyright to your article

Submit your next manuscript at $\boldsymbol{\nabla}$ springeropen.com 